\title{
Oxidized Galectin-1 Stimulates Macrophages to Promote Axonal Regeneration in Peripheral Nerves after Axotomy
}

\author{
Hidenori Horie, ${ }^{1,3,4}$ Toshihiko Kadoya, ${ }^{5}$ Naoshi Hikawa, ${ }^{4}$ Kazunori Sango, ${ }^{6}$ Hiroko Inoue, ${ }^{2}$ Kaori Takeshita, ${ }^{1}$ \\ Reiko Asawa, ${ }^{1}$ Tomoko Hiroi, ${ }^{1}$ Manami Sato, ${ }^{1}$ Tohru Yoshioka, ${ }^{2}$ and Yoshihiro Ishikawa ${ }^{4}$ \\ ${ }^{1}$ Advanced Research Center for Biological Science and ${ }^{2}$ School of Science and Technology, Waseda University, Nishitokyo City, Tokyo 202-0021, Japan, \\ ${ }^{3}$ Brain Information Science Laboratory, Corporate Research Center, Fuji Xerox, Kanagawa 259-0157, Japan, ${ }^{4}$ Departments of Physiology, School of \\ Medicine, Yokohama City University, Yokohama 236-0004, Japan, 5Pharmaceutical Research Laboratory, Kirin Brewery Company, Ltd., Takasaki 370-1295, \\ Japan, and ${ }^{\circ}$ Department of Developmental Morphology, Tokyo Metropolitan Institute for Neuroscience, Fuchu, Tokyo 183-8526, Japan
}

Various neurotrophic factors that promote axonal regeneration have been investigated in vivo, but the signals that prompt neurons to send out processes in peripheral nerves after axotomy are not well understood. Previously, we have shown oxidized galectin-1 (GAL-1/0x) promotes initial axonal growth after axotomy in peripheral nerves. However, the mechanism by which GAL-1/0x promotes axonal regeneration remains unclear and is the subject of the present study. To identify possible target cells of GAL-1/0x, a fluorescently labeled recombinant human GAL-1/0x (rhGAL-1/0x) was incubated with DRG neurons, Schwann cells, and intraperitoneal macrophages from adult rats. Only the cell surfaces of intraperitoneal macrophages bound the rhGAL-1/0x, suggesting that these cells possess a receptor for GAL-1/0x. Experiments examining tyrosine phosphorylation revealed that rhGAL-1/0x stimulated changes in signal transduction pathways in these macrophages. These changes caused macrophages to secrete an axonal growth-promoting factor. This was demonstrated when conditioned media of macrophages stimulated with rhGAL-1/0x in $48 \mathrm{hr}$ culture strongly enhanced axonal regeneration from transected-nerve sites of DRG explants. Furthermore, activated macrophage-conditioned media also improved Schwann cell migration from the transected-nerve sites. From these results, we propose that axonal regeneration occurs in axotomized peripheral nerves as a result of cytosolic reduced galectin-1 being released from Schwann cells and injured axons, which then becomes oxidized in the extracellular space. Oxidized galectin-1 then stimulates macrophages to secrete a factor that promotes axonal growth and Schwann cell migration, thus enhancing peripheral nerve regeneration.

Key words: oxidized galectin-1; nerve regeneration; macrophage; Schwann cell; peripheral nerve; initial regrowth

\section{Introduction}

Successful peripheral nerve regeneration requires the concerted interplay of non-neuronal cells, growth factors, cell adhesion molecules, extracellular matrix components, regenerating axons, and macrophage recruitment (Fawcett and Keynes, 1990; Bunge, 1993; Ide, 1996). Neurotrophic factors were once thought to regulate the initiation of axonal outgrowth after axotomy. However, recent findings in neurotrophic factors including NGF (Heumann et al., 1987; Lindholm et al., 1987; Verge et al., 1989; Funakoshi et al., 1993), brain-derived neurotrophic factor (BDNF; Yan et al., 1992; Koliatsos et al., 1993; Apfel et al., 1996), ciliaryderived neurotrophic factor (CNTF) (Friedman et al., 1992; Sendtner et al., 1992), and leukemia inhibitory factor (LIF) (Banner and Patterson, 1994) have put this into question. These fac-

Received 0ct. 2, 2003; revised Dec. 27, 2003; accepted Jan. 4, 2004.

This work was supported by a Grant-in-Aid for Scientific Research on Priority Areas, Advanced Brain Science Project, from the Ministry of Education, Culture, Sports, Science and Technology of Japan. We thank Dr. W. Tetzlaff and J. McGraw for helpful comments on this manuscript.

Correspondence should be addressed to Dr. Hidenori Horie, Advanced Research Center for Biological Science, Waseda University, Waseda University Higashifushimi Campus, 2-7-5 Higashifushimi, Nishitokyo City, Tokyo 2020021, Japan. E-mail: horie-hidenori@waseda.jp.

DOI:10.1523/JNEUROSCI.4483-03.2004

Copyright $\odot 2004$ Society for Neuroscience $\quad$ 0270-6474/04/241873-08\$15.00/0 tors have not been proved to satisfy essential conditions for initial axonal regeneration of localization of factors in injured region, promotion of axonal regeneration by application of them, or inhibition of axonal regeneration by antibodies against the factors. Unlike the neurotrophic factors mentioned above, insulinlike growth factor-I (IGF-I) expression increased significantly after transection of the sciatic nerve (Hansson et al., 1986; Glazner et al., 1994), and anti-IGF-I antibodies inhibit the regeneration of crushed sciatic nerves (Kanje et al., 1989). However, because IGF-I mRNA content at the site of injury does not increase until 4-6 d after nerve crush (Pu et al., 1995), the factors that prompt the axons to send out processes in peripheral nerves more rapidly after axotomy had not been well understood. Recent reports suggest that oxidized galectin- 1 facilitates the interplay of neuronal and non-neuronal cells after injury, thereby increasing the rate of initial axonal regeneration (Horie et al., 1999; Horie and Kadoya, 2000; Inagaki et al., 2000; Fukaya et al., 2003).

Galectin-1 is a member of a family of $\beta$-galactoside-binding lectins that is widely distributed throughout the animal kingdom. This lectin exists in both an oxidized and reduced state and only shows the lectin activity in its reduced state (Kasai and Hirabayashi, 1996; Perillo et al., 1998). Galectin-1 is intensely expressed 
in dorsal root ganglion neurons and motor neurons, with immunoreactivity localized to axons and Schwann cells of adult rodents (Regan et al., 1986; Hynes et al., 1990; Horie et al., 1999). We have demonstrated with in vivo as well as in vitro nerve regeneration models that only oxidized galectin-1(rhGAL-1/Ox), which exists as an oxidized form containing three intramolecular disulfide bonds $\left(\mathrm{Cys}^{2}-\mathrm{Cys}^{130}, \mathrm{Cys}^{16}-\mathrm{Cys}^{88}\right.$, and $\left.\mathrm{Cys}^{42}-\mathrm{Cys}{ }^{60}\right)$, and not reduced galectin-1 promotes axonal regeneration (Horie et al., 1999; Inagaki et al., 2000). Furthermore, in vivo peripheral nerve regeneration experiments with acellular autografts containing no viable cells and allografts containing no cell membranes clearly showed that rhGAL-1/Ox treatment promotes Schwann cell migration followed by axonal growth. Conversely, galectin-1 functional blocking antibodies strongly inhibited both Schwann cell migration and axonal outgrowth (Fukaya et al., 2003). These experiments demonstrate that rhGAL-1/Ox is an essential factor for initiating axonal regeneration in injured sensory and motor neurons. The next question to address is the mechanism by which oxidized galectin-1 regulates initial axonal regrowth. To accomplish this, the identity of the target cell of oxidized galectin-1 has to be determined. Because direct application of oxidized galectin-1 to isolated primary sensory neurons does not alter their morphology, we hypothesize that galectin-1 may stimulate non-neuronal cells to produce a factor that promotes Schwann cell migration while enhancing axonal regeneration. These nonneuronal cells may include Schwann cells, fibroblasts, and recruited macrophages.

In this paper we identify a target cell of oxidized galectin- 1 and elucidate the mechanism by which oxidized galectin-1 promotes axonal regeneration after peripheral nerve injury.

\section{Materials and Methods}

Preparation of rhGAL-1/Ox. rhGAL-1/Ox was obtained according to the previous methods (Inagaki et al., 2000). Briefly, rhGAL-1was expressed in Escherichia coli and purified from the supernatant of the sonicated $E$. coli by DEAE-HPLC. rhGAL-1 was oxidized from this bacterially expressed rhGAL-1 by the method of air oxidization catalyzed by CuSO4. DEAE-purified rhGAL- 1 was diluted 20 -fold with $20 \mathrm{~mm}$ Tris- $\mathrm{HCl}, \mathrm{pH}$ 8.0, $\mathrm{CuSO}_{4}$ was added to a final concentration of $0.0001 \%(\mathrm{w} / \mathrm{v})$, and the mixture was maintained overnight at $4^{\circ} \mathrm{C}$ to allow disulfide bond formation. rhGAL-1/Ox was purified by reversed-phase HPLC on a YMC-Pack Protein RP column (YMC) with a linear gradient of acetonitrile in $0.1 \%$ trifluoroacetic acid. Analysis by SDS-PAGE and HPLC showed that rhGAL-1/Ox was not degenerated even after $10 \mathrm{~d}$ incubation at $37^{\circ} \mathrm{C}$ in $\mathrm{PBS}$ (5 $\mu \mathrm{g}$ protein $/ \mathrm{ml})$.

Culture of peritoneal macrophages and their conditioned medium. The peritoneal cavity of a 14- to 16-week-old Wistar rat or C57BL/6 mouse was washed with a Ham's F-12 medium (Invitrogen, Carlsbad, CA). Peritoneal macrophages were obtained from the medium after double centrifugation. Macrophages were then seeded on noncoated culture dishes and weakly attached cells, which were different from macrophages, were washed out $10 \mathrm{~min}$ after the seeding. Using this method, we could obtain highly purified macrophages $(80 \%)$. The identity of the macrophages was verified using an anti-ED-1 antibody (Serotec, Oxford, UK) (Dailey et al., 1998).

Dissociation of dorsal root ganglion cells. Preparations were obtained from 3-month-old (young adult) Wistar rats or C57BL/6 mice from Nihon SLC (Shizuoka, Japan). They were anesthetized with ether and then killed. DRGs were carefully dissected and removed, and nerve fibers were severed at their base, adjacent to the dorsal root ganglion. Desheathed DRGs were obtained by the following procedure: an explant without nerve fibers was incubated in $0.25 \%$ collagenase (class III; Worthington, Lakewood, NJ) for $90 \mathrm{~min}$ at $37^{\circ} \mathrm{C}$. After washing with calcium- and magnesium-free HBSS (C-M-BSS), the explant was incubated in $0.25 \%$ trypsin (type IV; Sigma, St. Louis, MO) for $15 \mathrm{~min}$ at $37^{\circ} \mathrm{C}$. It was then washed three times with C-M-BSS containing $50 \mu \mathrm{g}$ $\mathrm{ml}^{-1}$ trypsin inhibitor (Sigma). Connective tissue was removed from the DRG, and the pooled DRGs [thoracic (T) 2-9] rsqb] were dissociated in a suspension of single cells by trituration after collagenase and trypsin treatment. These cells were added to 30\% Percoll (Amersham Biosciences, Piscataway, NJ) solution in which $\mathrm{pH}$ and osmolarity were adjusted. They were then subjected to density gradient centrifugation (5 min, $300 \times g$ ) that eliminated the myelin sheath. After double washing, cells were cultured on poly-L-lysine-coated (Sigma) plastic dishes in Ham's F-12 supplemented with 10\% fetal bovine serum (Invitrogen). Cells were composed mainly by sensory neurons, but with a small number of Schwann cells and satellite cells (Horie et al., 1989).

Fluorescent labeling of oxidized galectin-1. rhGAL-1/Ox was labeled using Alexa Fluor 488 labeling kit (Molecular Probes, Eugene, OR) following the manufacturer's instructions. Aliquots $(1 \mathrm{mg} / \mathrm{ml}, 500 \mu \mathrm{l})$ in PBS were combined with $50 \mu \mathrm{l}$ of $1 \mathrm{~m}$ sodium bicarbonate, $\mathrm{pH}$ 8.3. The solution was transferred to the vial of Alexa Fluor 488 and stirred for $1 \mathrm{hr}$ at room temperature. Seventeen microliters of hydroxylamine solution was added to the reaction vial and stirred for $30 \mathrm{~min}$ to stop the reaction. The solution was dialyzed extensively against PBS to remove free dye. The ratio of fluorescence labeled rhGAL-1/Ox was $\sim 0.85$ (moles dye per mole protein). FITC-conjugated bovine serum albumin (FITC-BSA; Sigma) was used as a nonspecific protein to clarify whether the labeled rhGAL-1/Ox binding is specific or not.

Measurement of tyrosine phosphorylation changes in macrophages after application of rhGAL-1/Ox. Rat macrophages were cultured with or without rhGAL-1/Ox for $5 \mathrm{~min}, 30 \mathrm{~min}, 2 \mathrm{hr}, 4 \mathrm{hr}$, and $8 \mathrm{hr}$. Control experiments to rhGAL-1/Ox were also performed using BSA (Sigma) for the same time courses. After incubation, macrophages were lysed in ice-cold lysis buffer by sonication. The lysate was separated by SDS-PAGE through a $10 \%$ gel. Proteins were transferred from the gel to a polyvinylidene difluoride membrane (Millipore, Bedford, MA). The membrane was incubated in anti-phosphorylated tyrosine antibody (PY20; IGN Biomedicals, Aurora, $\mathrm{OH}$ ) solution for $2 \mathrm{hr}$ after blocking with $1 \%$ BSA. After $1 \mathrm{hr}$ incubation in secondary antibody conjugated with HRP (goat anti-mouse IgG; Zymed, San Francisco, CA), immunoreactivity was visualized after development with ECL Plus Western blotting detection reagent (Amersham Biosciences) and scanning using a Molecular Imager FX (Bio-Rad, Hercules, CA).

Assay for axonal regeneration and Schwann cell migration in vitro. Axonal regeneration was detected with a three-dimensional culture of adult rat DRG explants as described previously (Horie et al., 1997). All preparations were obtained from 3-month-old Wistar rats (Nihon SLC). The rats were anesthetized with ether and killed. DRGs (T-2-9) of similar size with their associated nerve stumps, which were $1.0-2.0 \mathrm{~mm}$ in length, were carefully dissected, removed, and embedded in a collagen gel (thickness of the gel is $700 \mu \mathrm{m}$ to $1 \mathrm{~mm}$ ). The explants were then cultured at $37^{\circ} \mathrm{C}$ in $95 \%$ air: $5 \% \mathrm{CO}_{2}$ in Ham's $\mathrm{F} 12$ culture medium supplemented with $5 \mu \mathrm{g} / \mathrm{ml}$ insulin (Sigma), $5 \mu \mathrm{g} / \mathrm{ml}$ transferrin (Sigma), $2 \times 10^{-8} \mathrm{M}$ progesterone (Sigma), $0.1 \mathrm{~mm}$ putrescine (Sigma), and $3 \times 10^{-8}$ м sodium selenite (Sigma). The numbers of axons growing from each of these transected nerve sites were counted under a phase-contrast microscope at a region adjacent to the ends before they branched.

Effects of conditioned media on Schwann cell migration was demonstrated with the same culture method shown above in adult rat or C57BL/6 mouse DRG explants. Migrating Schwann cells cultured in Ham's F-12 supplemented with $10 \%$ fetal bovine serum were counted under the phase-contrast microscope.

Immunohistochemical identification of regenerating axons and migrating Schwann cells in collagen gel. The tissues were fixed with $4 \%$ paraformaldehyde overnight at $4^{\circ} \mathrm{C}$ and then washed for $24 \mathrm{hr}$ with PBS. An antibody against $\beta$ tubulin class III (Research Diagnostic, Flanders, NJ) or against high molecular neurofilament (RT97; Chemicon, Temecula, CA) was then applied for $2 \mathrm{~d}$. Because antibodies have a high molecular weight, they poorly penetrate the collagen gel, resulting in poor axonal labeling. To overcome this, a coverglass $(15 \times 15 \mathrm{~mm})$ was placed on the collagen and briefly pushed with forceps to stretch the gel without disrupting it. The gel acted like a sponge, enabling the antibody to permeate the gel and reach the tissues. This was repeated six times during the incubation with 100 times of repetitive push/release treatments in each 
trial, allowing antibodies to move into the tissues. After washing, a secondary antibody was applied for $2 \mathrm{~d}$ using the previously described method. This procedure clearly stained growing axons from a nervetransected site with anti-neurofilament antibody or anti- $\beta$ tubulin class III in $0.03 \%$ Triton X-100 in PBS. This method was also useful in immunohistochemical staining of migrating Schwann cells in the gel using the anti-S100 antibody (Dako, Carpinteria, CA).

Statistical analysis. Statistical analysis of the experiments was performed using Abacus Concepts, StatView for Macintosh (SAS Institute, Cary, NC). Significant differences between groups were determined by one-way ANOVA, followed by Scheffe's post hoc test. Data are presented as the mean \pm SEM. Values were considered significantly different with $p<0.05$.

\section{Results}

We have previously shown that GAL-1/Ox regulates the initial regrowth of axons in peripheral nerves after axotomy. However, it has not been clear how this factor initiates growth at a low concentration. To answer this question, we sought to identify galectin-1 receptor-expressing cells Oxidized galectin-1 binds to cell membranes of macrophages

We conjugated oxidized galectin-1 with a fluorescent probe (Alexa 488) to identify cells that would bind GAL-1/Ox. This labeled rhGAL-1/Ox was applied to dissociated DRGs that included neurons, Schwann cells, satellite cells, and fibroblasts. Under fluorescent microscopy, no fluorescence could be observed on any of the surfaces of the dissociated cells (Fig. $1 B$ ). As mentioned in previous papers (Horie et al., 1999), rhGAL-1/Ox did not affect DRG neuron morphology or neurite extension in vitro. The lack of a morphological effect of rhGAL-1/Ox on axonal growth of dissociated DRG neurons might be attributable to the absence of neuronal GAL-1/Ox-specific receptors. Although GAL-1/Ox promotes Schwann cell migration in vivo, they may not possess GAL-1/Ox receptors either because the morphology and migration rate of Schwann cells in $10 \%$ serum-containing media were not affected by rhGAL-1/Ox treatment in vitro. In comparison, the outer membranes of macrophages obtained from adult rat peritoneal cavities were well stained with the labeled rhGAL-1/Ox. A cold incubation of rhGAL-1/Ox and macrophages was performed to prevent macrophage phagocytosis (Ito et al., 1981; Peiser et al., 2000), thereby allowing specific labeling of the macrophage cell surface (Fig. $1 D$ ). Control experiments using BSA supported these results. Addition of $100 \mu \mathrm{g} / \mathrm{ml}$ BSA to the labeling media did not change the labeling of the rhGAL-1/Ox-bound macrophages. This result was confirmed when FITC-conjugated BSA was incubated with macrophages. Macrophages showed no FITC on their cell surfaces or cell bodies after $10 \mathrm{~min}$ incubation in the media containing $10 \mu \mathrm{g} / \mathrm{ml}$ or 100 $\mu \mathrm{g} / \mathrm{ml}$ FITC-BSA at $0^{\circ} \mathrm{C}$. These results suggest that macrophages are a target cell of oxidized galectin- 1 and they may possess specific receptors to oxidized galectin-1. This possibility was confirmed by the incubation of nonlabeled rhGAL-1/Ox before the application of the fluorescently labeled rhGAL-1/Ox. We observed that a $20 \mathrm{~min}$ preincubation with $50 \mu \mathrm{g} / \mathrm{ml}$ nonlabeled rhGAL-1/Ox strongly inhibited the binding fluorescent labeled rhGAL-1, which was incubated for $10 \mathrm{~min}$ at a concentration of $0.5 \mu \mathrm{g} / \mathrm{ml}$. (Fig. $1 F$ ).

\section{Oxidized galectin-1 stimulates tyrosine phosphorylation of proteins in macrophages}

Purified macrophages were incubated in media containing 500 $\mathrm{pg} / \mathrm{ml} \mathrm{rhGAL}-1 / \mathrm{Ox}$ for $5 \mathrm{~min}, 30 \mathrm{~min}, 2 \mathrm{hr}, 4 \mathrm{hr}$, and $8 \mathrm{hr}$, or in $2.5 \mathrm{ng} / \mathrm{ml} \mathrm{BSA}$-containing media (equivalent mole concentration to rhGAL-1/Ox). Figure $2 A$ shows that rhGAL-1/Ox application

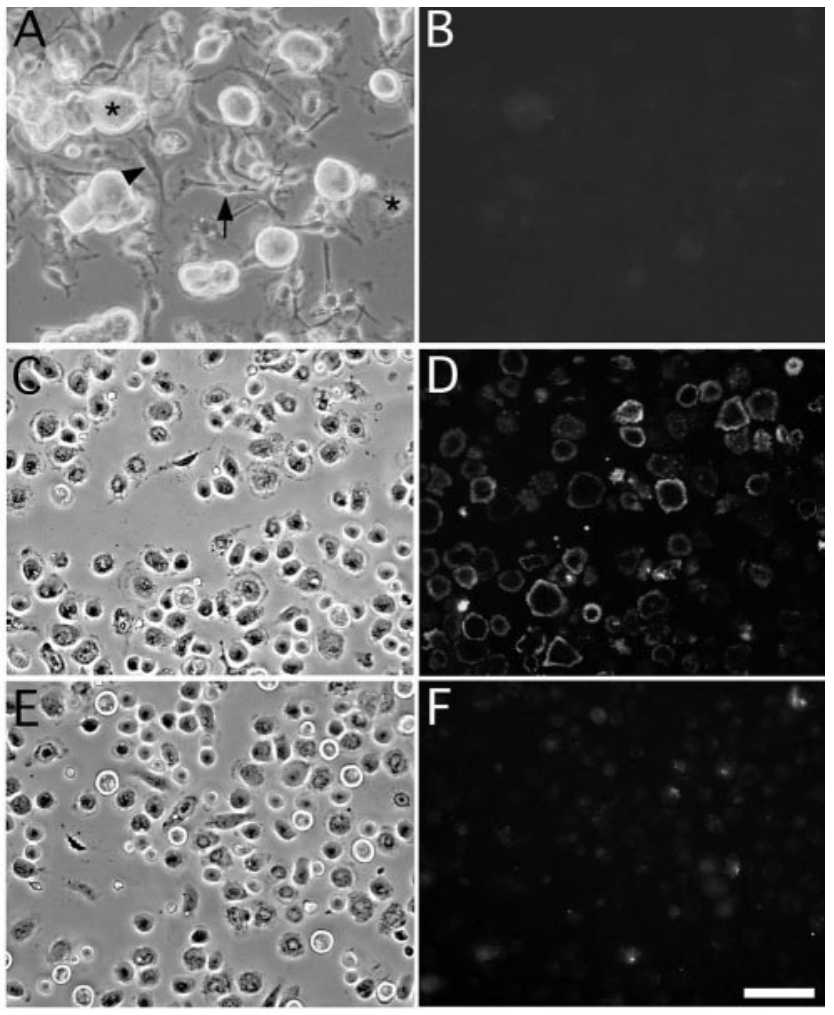

Figure 1. 0xidized galectin-1 binds to cell membranes of macrophages. Cells dissociated from DRGs include sensory neurons $\left(^{*}\right)$, Schwann cells $(\rightarrow)$, satellite cells $(\star)$, and fibroblasts ( $\boldsymbol{\nabla}$ ) (Fig. A). These cells were incubated at $37^{\circ} \mathrm{C}$ for $10 \mathrm{~min}$ in a solution containing $0.5 \mu \mathrm{g} / \mathrm{ml}$ fluorescence-conjugated rhGAL-1/0x. No cells showed immunoreactivity with this treatment $(B)$. Peritoneal macrophages $(C)$ were incubated at $0^{\circ} \mathrm{C}$ for $10 \mathrm{~min}$ in a solution containing 0.5 $\mu \mathrm{g} / \mathrm{ml}$ fluorescence-conjugated rhGAL-1/0x. After washing out the free fluorescent-labeled rhGAL-1/0x from culture dishes, fluorescence is located only on cell surfaces of macrophages (D). Twenty minutes of pretreatment with fluorescence-free rhGAL-1/0x (50 $\mu \mathrm{g} / \mathrm{ml})$ inhibited this labeling $(F)$. These results suggest that macrophages bear specific receptors to $\mathrm{rhGAL}-1 / 0 \mathrm{x}$ on their cell membranes. Scale bar, $50 \mu \mathrm{m}$.

changes tyrosine phosphorylation in two bands, as indicated by the arrows. They were initially upregulated and then decreased over $8 \mathrm{hr}$. The bands did not change after BSA treatment (Fig. $2 B$ ). These rhGAL-1/Ox-induced changes in phosphorylation suggest that rhGAL-1/Ox specifically binds to macrophages to activate their signal transduction pathways. It is plausible that rhGAL-1/Ox stimulates macrophages by activating protein synthesis and possibly the release of proteins to promote axonal regeneration.

\section{Oxidized galectin-1 induces macrophages to secrete a factor or factors to promote axonal regeneration}

Four kinds of media were prepared: (1) a serum-free control medium, (2) a $500 \mathrm{pg} / \mathrm{ml}$ rhGAL-1-containing medium, (3) a nonactivated macrophage-conditioned medium without rhGAL$1 / \mathrm{Ox}$ after $2 \mathrm{~d}$ culture, and (4) a rhGAL-1/Ox-activated macrophage-conditioned medium after $2 \mathrm{~d}$ culture. Using DRG explants, the effect of these media on axonal regeneration was examined. These DRGs had nerve stumps still attached that extend in two opposite directions: one bundle extended toward the spinal cord, and the other extended toward sensory organs or muscles. Here, the former is termed the central nerve stump and the latter the peripheral nerve stump. Processes extending from nerve transection sites in collagen gels were identified as axons using antibodies against $\beta$-tubulin class III or phosphorylated 


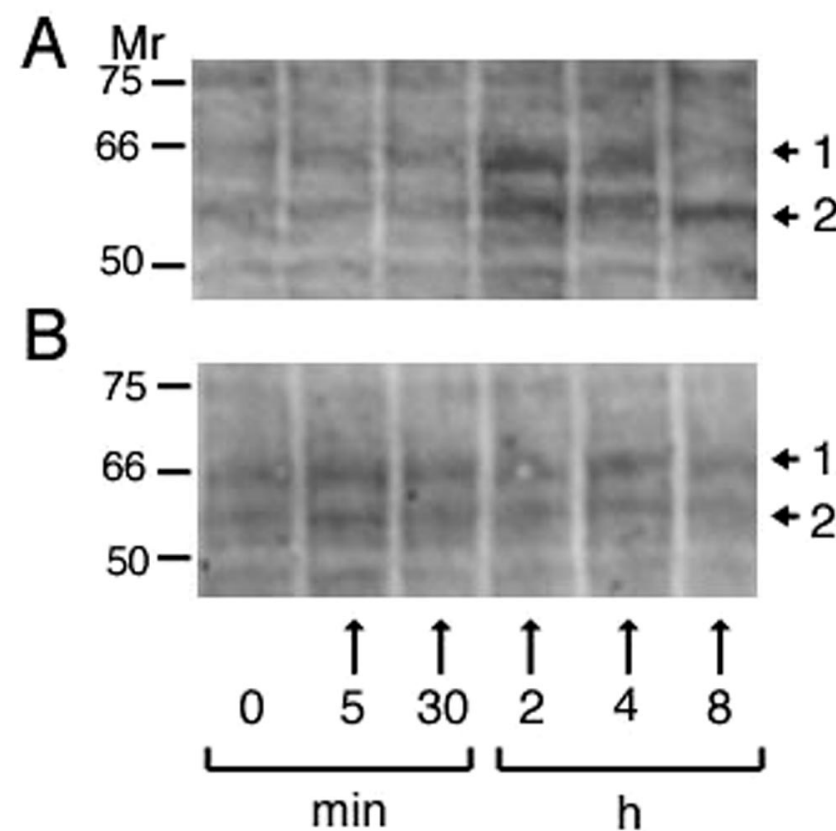

Figure 2. 0xidized galectin-1 stimulates macrophages to change the tyrosine phosphorylation of proteins. Peritoneal macrophages were cultured for $8 \mathrm{hr}$ in six culture dishes containing Ham's F-12 medium in treatment in the presence or absence of rhGAL-1/0x $(A)$ or BSA $(B)$. Numbers in horizontal bar indicate incubation time: 0 ; cultured in the absence of rhGAL-1/0x or BSA, $5 \mathrm{~min}, 30 \mathrm{~min}, 2 \mathrm{hr}, 4 \mathrm{hr}, 8 \mathrm{hr}$; cultured for each corresponding time in the presence of rhGAL-1/0x or BSA. The same cultures were lysed in ice-cold lysis and then analyzed by Western blotting with anti-phosphorylated tyrosine antibody. The arrows from 1 and 2 indicate the tyrosine-phosphorylated bands whose intensities change with incubation time in case of the treatment with rhGAL-1. Molecular weights of these bands are 65 and $56 \mathrm{kDa}$, respectively.

high molecular neurofilament, described in Materials and Methods. After the application of the different media treatments to the DRG explants, an axonal regeneration-promoting effect was clearly seen with the activated conditioned medium after $6 \mathrm{~d}$ in culture (Fig. 3). Conditioned medium from nonactivated macrophages also increased the number of regenerating axons from the transected-nerve site of adult DRG explants in comparison with the control (Fig. $3 A, B$ ). Furthermore, the activated medium intensely enhanced axonal regeneration in comparison with the nonactivated conditioned medium (Fig. 3B,C). Statistical analysis confirmed these experiments' results (Fig. 4). Figure $4 A$ shows that conditioned media promoted axonal regeneration compared with the control after $3 \mathrm{~d}$ in culture, and this effect was even stronger at $6 \mathrm{~d}$ and beyond (Fig. $4 B, C)(p<0.01$ between the activated medium and the other three conditions). This enhancement of axonal regeneration by rhGAL-1/Ox conditioned media was not significantly reduced by addition of a functional blocking GAL-1 antibody to the cultured DRG explants (Fig. 5). However, this antibody significantly inhibited the axonal regenerationpromoting activity of oxidized galectin- 1 when the antibody was used in conjunction with rhGAL-1/Ox (Fig. 6). These results suggest that rhGAL-1/Ox stimulates macrophages to secrete one or more factors that promote axonal regeneration.

\section{rhGAL-1/Ox stimulates macrophages to enhance Schwann cell migration}

The DRG explants were cultured in collagen gels with $10 \%$ serum-containing medium. The effects of the conditioned medium on Schwann cell migration, identified using antibodies against $\mathrm{S} 100$, from the central site of the transected nerve sites was
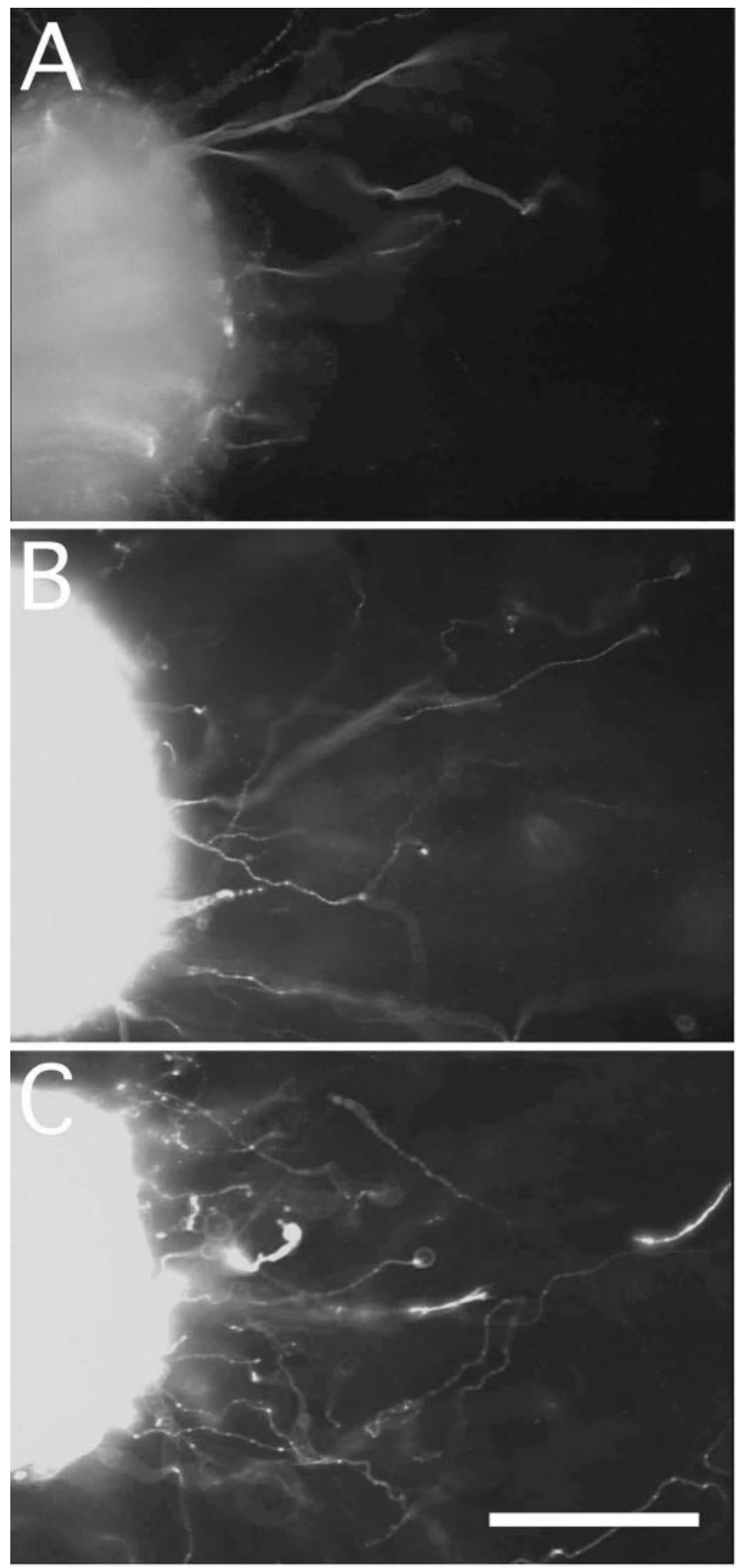

Figure 3. 0xidized galectin-1 induces macrophages to secrete an axonal regenerationpromoting factor. DRG explants were cultured in either a serum-free defined medium ( $A$, control), macrophage-conditioned media in the absence of rhGAL-1/0x (B), or rhGAL-1/0xstimulated macrophage-conditioned media ( $C$. All explants were taken after $6 \mathrm{~d}$ in culture and immunohistochemically stained with an antibody against $\beta$-tubulin class III. Pictures show that rhGAL-1/0x-stimulated macrophages secrete a factor that promotes axonal regeneration. Numbers of regenerating axons from the nerve-transected sites were $35(A), 70(B)$, and $99(C)$, respectively. Scale bar, $200 \mu \mathrm{m}$.

measured. No differences were observed when explants were cultured in a rhGAL-1/Ox-containing medium $(500 \mathrm{pg} / \mathrm{ml})$, when compared with controls. However, rhGAL-1/Ox-stimulated macrophage conditioned medium strongly enhanced Schwann cell migration compared with the control medium (Fig. 7). The 

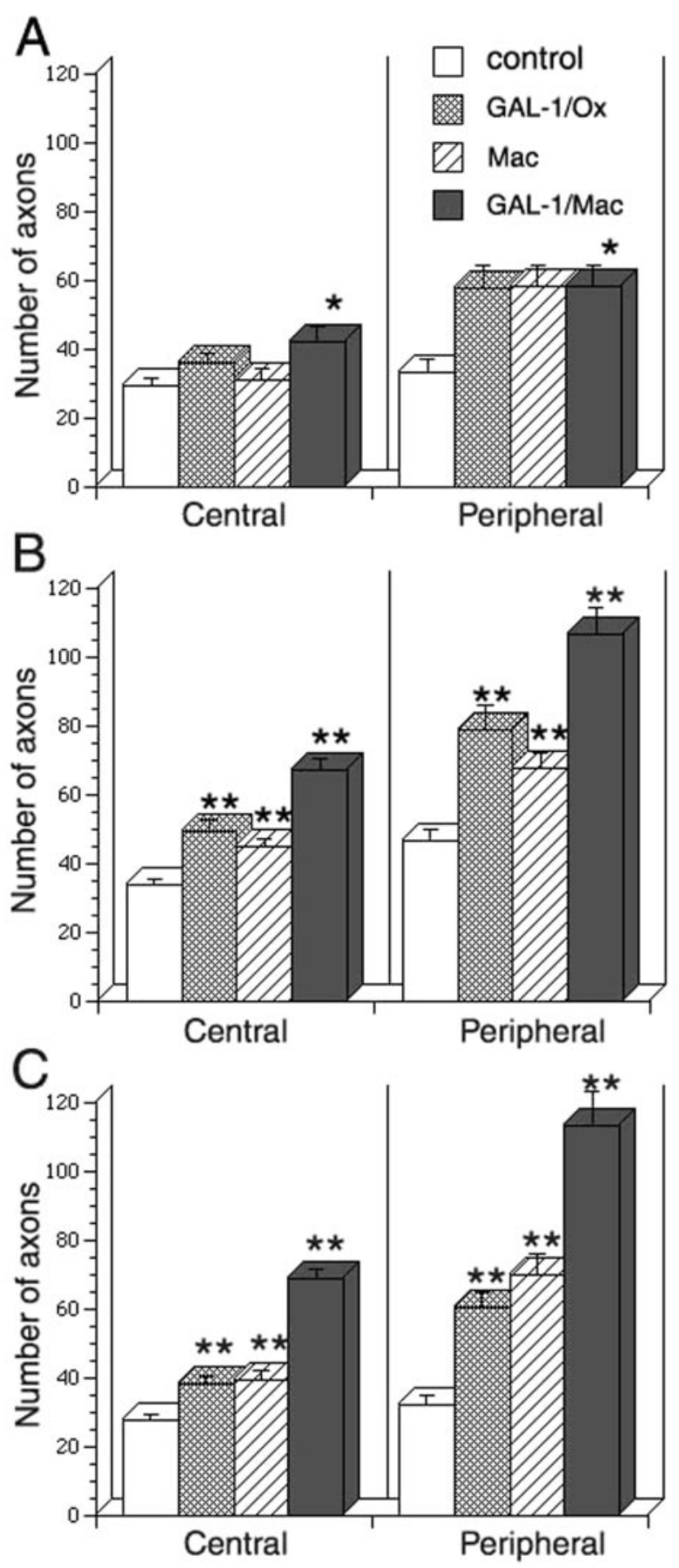

Figure 4. Conditioned media from rhGAL-1/0x-stimulated macrophages enhances axonal regeneration. The effect of conditioned media from rhGAL-1/0x-stimulated macrophage (Mac) on axonal regeneration was compared with three other media. 1, Control: a serum-free control medium; 2, GAL-1/0x: a $500 \mathrm{pg} / \mathrm{ml}$ rhGAL-1 containing medium, 3, Mac: a nonactivated macrophage-conditioned medium without rhGAL-1/0x, 4, GAL-1/Mac: conditioned medium from rhGAL-1/0x-activated macrophages. $A$, After $3 \mathrm{~d}$ in culture; $B, 6 \mathrm{~d}$ in culture; $C, 10 \mathrm{~d}$ in culture. Numbers $(n)$ of experiments in each medium are the same in $A-C$. In central the numbers are 12 common in four different media. In peripheral those are 11 (control), 9 (GAL1/0x), 11 (Mac), and 9 (GAL-1/Mac), respectively. ${ }^{*} p<0.05$ and ${ }^{* *} p<0.01$, significantly different from conditioned medium from rhGAL-1/0x-activated macrophages.

numbers of Schwann cells migrating further than $300 \mu \mathrm{m}$ from the transected site in the activated conditioned medium (86.4 \pm 13.8; mean \pm SEM; $n=7)$ was significantly higher than in controls after $4 \mathrm{~d}$ in culture $(25.7 \pm 4.4 ; n=10 ; p<0.01)$. A similar

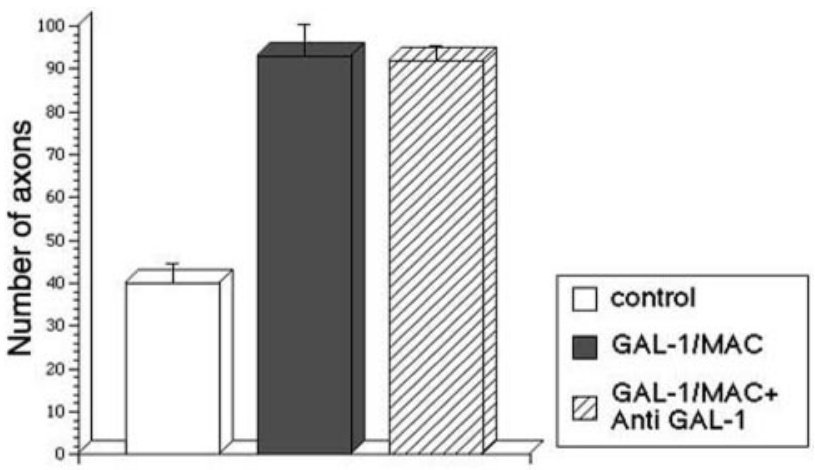

Figure 5. No significant effect of anti-GAL-1 antibody on axonal promoting activity of conditioned medium from rhGAL-1/0x-activated macrophage. DRG explants were cultured in three kinds of serum-free defined media. 1, Control: a serum-free medium; 2, GAL-1/MAC: a conditioned medium from rhGAL-1/0x-activated macrophages; and 3, GAL-1/MAC + anti-GAL-1: 10 $\mu \mathrm{g} / \mathrm{ml}$ anti-GAL-1 antibody + conditioned medium from rhGAL-1/0x-activated macrophages. Figure shows average numbers of regenerating axons from the peripheral site after $6 \mathrm{~d}$ in culture. Numbers $(n)$ of experiments in each medium are 6 (control), 7 (GAL-1/MAC), and 6 (GAL-1/MAC + anti-GAL-1). There was no significant difference between GAL-1/MAC and GAL-1/MAC + anti-GAL-1.

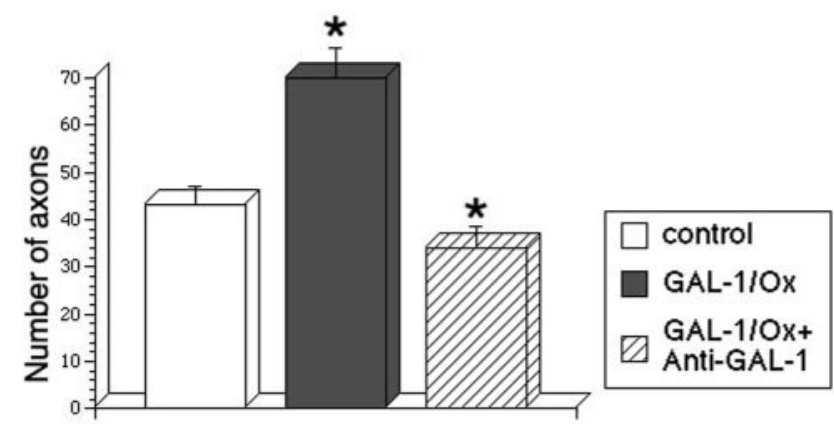

Figure 6. Inhibitory effect of anti-GAL-1 antibody on axonal promoting activity of GAL-1/0x. DRG explants were cultured in three kinds of serum-free defined media. 1, Control: a serum-free medium; 2, GAL-1/0x: a 100 pg/ml GAL-1/0x-containing medium; and 3, GAL-1/0x + antiGAL-1: a $10 \mu \mathrm{g} / \mathrm{ml}$ anti-GAL-1 antibody $+100 \mathrm{pg} / \mathrm{ml}$ GAL-1/0x containing medium. Figure shows average numbers of regenerating axons from the peripheral site after $6 \mathrm{~d}$ in culture. Numbers $(n)$ of experiments in each medium are 7 (control), 8 (GAL-1/0x), and 6 (GAL-1/0x + anti-GAL-1). ${ }^{*} p<0.01$, significantly different between GAL-1/0x and GAL-1/0x + anti-GAL-1.

growth-promoting effect was also seen at $6 \mathrm{~d}$ in culture. In the central site, the numbers migrating longer than $500 \mu \mathrm{m}$ were $60.6 \pm 6.7(n=10)$ in control and 116.1 $\pm 17.7(n=6)$ in the conditioned medium $(p<0.01)$. Although in the peripheral site, Schwann cell migration was slower than that in central site, the conditioned medium also promoted the migration. At $6 \mathrm{~d}$ in culture those migrating longer than $300 \mu \mathrm{m}$ were $36.5 \pm 5.5(n=$ $6)$ in control and $72.1 \pm 11.5(n=6)$ in the conditioned medium $(p<0.05)$. These results indicate that Schwann cell migration was strongly enhanced by the rhGAL-1/Ox activated medium from central and peripheral nerve-transected sites. The enhancement of Schwann cell migration is another essential function of oxidized galectin-1-stimulated macrophage-conditioned medium for peripheral nerve regeneration (Bunge, 1993; Ide, 1996).

\section{Discussion}

The damaged region in a peripheral nerve injury attracts cells recruited from the blood that aid in the repair of the wound site for neuronal regeneration. However, the initiating factors of axonal regrowth after axotomy have not been identified. We have previously shown that oxidized galectin-1 regulates the initial 

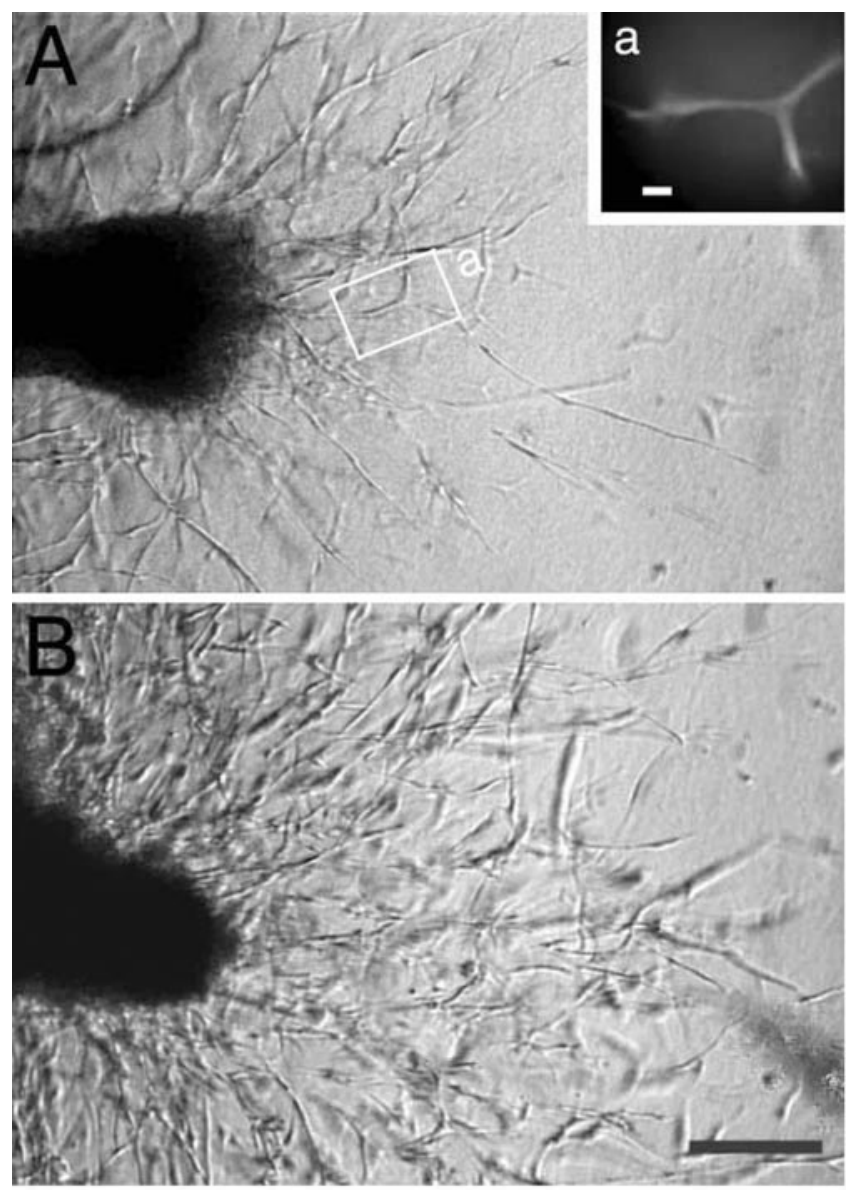

C

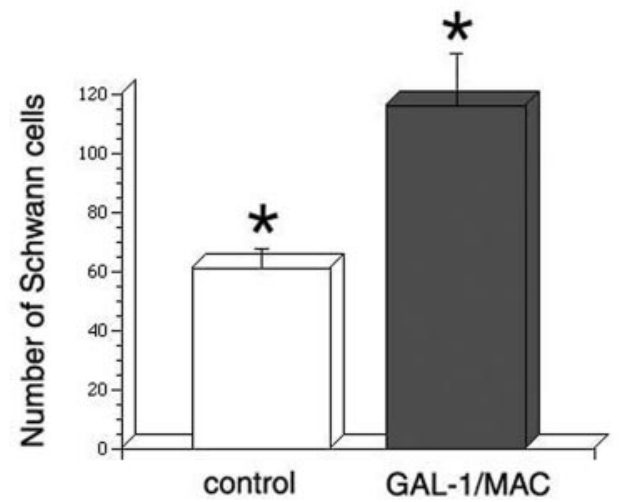

Figure 7. Conditioned medium from rhGAL-1/0x-stimulated macrophages promotes Schwann cell migration from a transected site of a cultured DRG explant with an associated nerve stump. Pictures of migrating Schwann cells from a central transected-nerve site were taken after $4 \mathrm{~d}$ in culture. Numbers of Schwann cells migrating longer than $300 \mu \mathrm{m}$ from the transected site are 22 in the control $(A)$ and 86 in cultures treated with conditioned medium $(B)$. As shown in $A a$, the same region indicated by a white rectangular line in $A$, migrating cells were positive to immunohistochemical staining with antibody against $S 100$. Scale bars: $a, 20 \mu \mathrm{m} ; B$, $100 \mu \mathrm{m}$. This effect of the conditioned medium was also seen in the central site after $6 \mathrm{~d}$ in culture. The Schwann cell numbers migrating longer than $500 \mu \mathrm{m}$ in the conditioned medium $(n=10)$ is specifically larger than a control medium $(n=7)(p<0.01)$.

process of axonal regeneration (Horie et al., 1999; Horie and Kadoya, 2000). Application of rhGAL-1/Ox to the injured region in sciatic nerves promoted Schwann cell migration together with axonal growth, whereas treatment with a functional blocking GAL-1 antibody strongly inhibited Schwann cell migration as well as axonal regrowth (Horie et al., 1999; Fukaya et al., 2003).
Because galectin-1 exists in a reduced dimeric form in motor and sensory neurons as well as in Schwann cells, it is possible that within the damaged region, axons, and especially their growth cones, and Schwann cells may release reduced galectin-1 after nerve injury. Some of these released molecules become quickly oxidized in the extracellular space (Tracey et al., 1992; Kasai and Hirabayashi, 1996; Horie and Kadoya, 2000). We have previously shown that oxidized galectin-1 loses lectin activity and is able to enhance axonal growth at low concentrations. However, the target cell of the released factor and how it works had not been clarified. Here we further demonstrate that by binding to specific macrophage receptors, GAL-1/Ox initiates protein phosphorylation. Direct application of rhGAL-1/Ox to DRG neurons did not show any neurite-promoting activity nor did it affect cell survival. It is thought that GAL-1/Ox works on non-neuronal cells in the damaged region.

\section{Macrophages are a target cell of oxidized galectin-1}

Application of fluorescence-conjugated rhGAL-1/Ox to dissociated cells of DRG, such as neurons, Schwann cells, and peritoneal macrophages showed that only the cell surface of macrophages was clearly labeled (Fig. 1). This indicates that rhGAL-1/Ox only binds to macrophages. Because macrophages are located within the DRG (Perry, 1994), these data may explain the axonal regeneration promoting activity of rhGAL-1/Ox in DRG explants (Fig. 4). Given that oxidized galectin-1 lacks lectin activity, the labeled GAL-1/Ox may bind to specific oxidized-galectin-1 receptors on the cell membrane, but not to glycoproteins on macrophage cell surfaces. This binding of oxidized galectin-1 evokes an intracellular signal transduction pathway in macrophages (as indicated by protein phosphorylation, Fig. 2), which may result in the expression and/or release of trophic factors. Although further experiments are needed to clarify the signal transduction pathways activated after identification of the receptor, this work indicates that macrophages stimulated by oxidized galectin-1 are important in peripheral nerve regeneration.

\section{Oxidized galectin-1 stimulates macrophages to release a factor essential for axonal regeneration}

Several roles for macrophages in axonal regeneration process have been proposed, including (1) removal of substances inhibiting axonal regeneration, (2) secretion of proteases to modify ECM and adhesion molecules, (3) release of factors promoting Schwann cell secretion of growth factors, (4) secretion of growth factors or cofactors for axonal growth, and (5) secretion of factors or cofactors promoting remyelination (Perry, 1994). This paper has shown that oxidized galectin-1 stimulates macrophages to release a factor that promotes axonal regeneration and Schwann cell migration (Figs. 3, 4, 7), supporting possibilities (2), (3), and (4) listed above. The result also offers a possible interpretation of the work of Rapalino et al. (1999) and Schwartz et al. (1999). These authors have shown that macrophages, which were preexposed to degenerating peripheral nerves, can facilitate the processes of regeneration in the severed spinal cord. Because the peripheral nerve segments include oxidized galectin-1, this factor may stimulate macrophages to facilitate axonal regeneration. If this hypothesis is correct, this factor can aid in repairing damaged neurons and restoring integrity after injury. Evidence already exists that macrophages express neurotrophins, specific receptors, various cytokines, adhesion molecules, and extracellular matrix molecules (Elkabes et al., 1996; Ricci et al., 2000). Using the same in vitro DRG explant model, we have already demonstrated various neurotrophic factors (NGF, IGF-I, IGF-II, CNTF) 
and cytokines (IL-1 $\beta$, IL-6) promote axonal regeneration (Horie et al., 1994, 1997; Akahori and Horie, 1997; Shuto et al., 2001). Surprisingly, the axonal promoting activity of the GAL-1/Oxactivated macrophage conditioned medium is distinctively stronger than those trophic factors. Furthermore, known neurotrophic factors are not thought to be an initial axonal promoting factor. These results indicate that a different factor may be released from the macrophages. Analysis with ultrafiltration membranes showed that the activity was in a retained fraction $(>10$ $\mathrm{kDa}$ ) of rhGAL-1/Ox stimulated macrophage-conditioned medium (reference or data not shown). This putative factor may be a protein because activity was diminished after heating this medium at $95^{\circ} \mathrm{C}$ for $5 \mathrm{~min}$. Interestingly, Zymosan, a yeast cell wall preparation, induces macrophages to secrete a factor that stimulates optic nerve regeneration (Yin et al., 2003). This factor was thought to be a protein with an apparent size of $14 \mathrm{kDa}$ that is distinct from known neurotrophic factors. Further experiments will identify whether the factor released from GAL-1/Oxstimulated macrophages is the same factor as that released from Zymosan-stimulated macrophages.

\section{Initial axonal regeneration process after sciatic nerve injury}

This work presents a plausible hypothesis about the initial cascade of events in axonal regeneration, as regulated by oxidized galectin-1 after sciatic nerve injury. This process is composed of the following three stages: stage I, Injury; stage II, initiation of axonal regrowth; stage III, nerve reconstruction.

The sciatic nerve contains sympathetic neurons as well as sensory and motor neurons. These axons and Schwann cells have been shown to express reduced galectin-1 (Dodd and Jessell, 1986; Regan et al., 1986; Hynes et al., 1990; Horie et al., 1999). These galectin-1 molecules are thought to be released into the injured extracellular space. In stage I, when sciatic nerves are injured, axons are damaged, and Schwann cells are also damaged or stimulated to become reactive. After damage, monocytes quickly flow into the injured space from blood to become macrophages (Perry, 1994; Hughes and Perry, 2000). In stage II, axons in a sciatic nerve stump are sealed at the injured site and initiate formation of a growth cone. From these axons, especially from their growth cones, reduced galectin-1 can be secreted via noncharacterized pathways (Johnston and Wessells, 1980; Cooper and Barondes, 1990; Avellana-Adalid et al., 1994; Cho and Cummings, 1995; Lutomski et al., 1997; Horie et al., 1999). Reactive Schwann cells may also secrete reduced galectin-1 in the same manner to their cell surfaces. Some of the galectin-1 molecules bind to $\beta$-galactosides located on cell surfaces, but others may be free from the carbohydrates to enter the extracellular space. Damaged axons and Schwann cells lose their membrane regulation of substance permeability, allowing cytosolic galectin-1 to enter the extracellular space. These reduced galectin-1 molecules in the extracellular space are easily oxidized, forming three disulfide bonds, resulting in the loss of lectin activity (Inagaki et al., 2000). Injury-induced nitric oxide (NO) in the extracellular space (Levy et al., 2000) may accelerate the oxidization of reduced galectin-1 to oxidized galectin-1. These oxidized galectin-1 molecules are thought to promote Schwann cell migration and aid in axonal regeneration (Horie et al., 1999). As shown in Figure 1, oxidized galectin-1 binds to a specific receptor on macrophages, which initiates a signal transduction cascade in macrophages and leads to the secretion of an unidentified factor that promotes axonal regrowth and Schwann cell migration (Figs. 2-4, 7). Stage III presents a hypothesis about the nerve regenerating process after axotomy. In vivo, peripheral nerve re- generation experiments, with acellular autografts containing no viable cells or allografts containing no cell membranes, clearly showed that treatment with rhGAL-1/Ox promotes Schwann cell migration followed by axonal growth of neurons (Fukaya et al., 2003). Conversely, the antibody treatment against galectin-1 strongly inhibited both migration and nerve regrowth (Fukaya et al., 2003). Because oxidized galectin-1 itself does not improve Schwann cell migration, an unidentified factor could enhance Schwann cell migration in the in vivo experiments (Fig. 7). These results indicate that regenerating axons follow migrating Schwann cells in regenerating peripheral nerves, as shown in stage III. It is concluded that this work helps to clarify the roles of oxidized galectin-1 in the initial stages of axonal regeneration in peripheral nerves.

\section{References}

Akahori Y, Horie H (1997) IGF-I enhances neurite regeneration but is not required for its survival in adult DRG explant. NeuroReport 8:2265-2269.

Apfel SC, Wright DE, Wiideman AM, Dormia C, Snider WD, Kessler JA (1996) Nerve growth factor regulates the expression of brain derived neurotrophic factor mRNA in the peripheral nervous system. Mol Cell Neurosci 7:134-142.

Avellana-Adalid V, Rebel G, Caron M, Cornillot JD, Bladier D, JoubertCaron R (1994) Changes in S-type lectin localization in neuroblastoma cells (N1E115) upon differentiation. Glycoconj J 11:286-291.

Banner LR, Patterson PH (1994) Major changes in the expression of the mRNAs for cholinergic differentiation factor/leukemia inhibitory factor and its receptor after injury to adult peripheral nerves and ganglia. Proc Natl Acad Sci USA 91:7109-7113.

Bunge RP (1993) Expanding roles for the Schwann cell: ensheathment, myelination, trophism and regeneration. Curr Opin Neurobiol 3:805-809.

Cho M, Cummings RD (1995) Galectin-1, a beta-galactoside-binding lectin in Chinese hamster ovary cells. II. Localization and biosynthesis. J Biol Chem 270:5207-5212.

Cooper DNW, Barondes SH (1990) Evidence for export of a muscle lectin from cytosol to extracellular matrix and for a novel secretory mechanism. J Cell Biol 110:1681-1691.

Dailey AT, Avellino AM, Benthem L, Silver J, Kliot M (1998) Complement depletion reduces macrophage infiltration and activation during Wallerian degeneration and axonal regeneration. J Neurosci 18:6713-6722.

Dodd J, Jessell TM (1986) Cell surface glycoconjugates and carbohydrate binding proteins: possible recognition signals in sensory neuron development. J Exp Biol 124:225-238.

Elkabes S, DiCicco-Bloom EM, Black IB (1996) Brain microglia/macrophages express neurotrophins that selectively regulate microglial proliferation and function. J Neurosci 16:2508-2521.

Fawcett JW, Keynes RJ (1990) Peripheral nerve regeneration. Annu Rev Neurosci 13:43-60.

Friedman B, Scherer SS, Rudge JS, Morrisey D, McClain J, Wang DY, Wiegand SJ, Furth ME, Lindsay RM, Ip NY (1992) Regulation of ciliary neurotrophic factor expression in myelin related Schwann cells in vivo. Neuron 9:295-305.

Fukaya K, Hasegawa M, Mashitani T, Kadoya T, Horie H, Hayashi Y., Fujisawa H, Tachibana O, Kida S, Yamashita, J (2003) Oxidized galectin-1 stimulates the migration of Schwann cells from both proximal and distal stumps of transected nerves and promotes axonal regeneration after peripheral nerve injury. J Neuropathol Exp Neurol 62:162-172.

Funakoshi H, Frisen J, Barbany G, Timmusk T, Zachrisson O, Verge VMK, Persson H (1993) Differential expression of messenger RNAs for neurotrophins and their receptors after axotomy of the sciatic nerve. J Cell Biol 123:455-465.

Glazner GW, Morrison AE, Ishii DN (1994) Elevated insulin-like growth factor (IGF) gene expression in sciatic nerves during IGF-supported nerve regeneration. Mol Brain Res 25:265-272.

Hansson HA, Dahlin LB, Danielsen N, Fryklund L, Nachemson AK, Polleryd P, Rozell B, Skottner A, Stemme S, Lundborg G (1986) Evidence indicating trophic importance of IGF-I in regenerating peripheral nerves. Acta Physiol Scand 126:609-614.

Heumann R, Lindholm D, Bandtlow C, Meyer M, Radeke MJ, Misko TP, Shooter E, Thoenen H (1987) Differential regulation of mRNA encod- 
ing nerve growth factor and its receptor in rat sciatic nerve during development, degeneration, and regeneration: role of macrophages. Proc Natl Acad Sci USA 84:8735-8739.

Horie H, Kadoya T (2000) Identification of oxidized galectin-1 as an initial repair regulatory factor after axotomy in peripheral nerves. Neurosci Res 38:131-137.

Horie H, Ikuta S, Takenaka T, Ito S (1989) Adaptation of cultured mammalian neurons to a hypotonic environment with age-related response. Brain Res 477:233-240.

Horie H, Sakai I, Akahori Y, Kadoya T (1997) IL-1 $\beta$ enhances neurite regeneration from transected-nerve terminals of adult rat DRG. NeuroReport 8:1955-1959.

Horie H, Inagaki Y, Sohma Y, Nozawa R, Okawa K, Hasegawa M, Muramatsu N, Kawano H, Horie M, Koyama H, Sakai I, Takeshita K, Kowada Y, Takano M, Kadoya T (1999) Galectin-1 regulates initial axonal growth in peripheral nerves after axotomy. J Neurosci 19:9964-9974.

Hughes PM, Perry VH (2000) The role of macrophages in degeneration and regeneration in the peripheral nervous system. In: Degeneration and regeneration in the nervous system (Saunders N, Dzieqielewska KM, Saunders NR, eds), pp 263-283. The Netherlands: Harwood Academic.

Hynes MA, Gitt M, Barondes SH, Jessell TM, Buck LB (1990) Selective expression of an endogenous lactose-binding lectin gene in subsets of central and peripheral neurons. J Neurosci 10:1004-1013.

Ide C (1996) Peripheral nerve regeneration. Neurosci Res 25:101-121.

Inagaki I, Sohma Y, Horie H, Kadoya T (2000) Oxidized galectin-1 promotes axonal regeneration in peripheral nerves but does not possess lectin properties. Eur J Biochem 267:2955-2964.

Johnston RN, Wessells NK (1980) Regulation of the elongation nerve fiber. Curr Topics Dev Biol 16:165-206.

Ito T, Ueda MJ, Okada TS, Ohnishi S (1981) Phagocytosis by macrophages. II. The dissociation of the attachment and ingestion steps. J Cell Sci 51:189-201.

Kanje M, Skottner A, Sjoberg J, Lundborg G (1989) Insulin-like growth factor (IGF-1) stimulates regeneration of the rat sciatic nerve. Brain Res 486:396-398.

Kasai K, Hirabayashi J (1996) Galectins: a family of animal lectins that decipher glycocodes. J Biochem 119:1-8.

Koliatsos VE, Clatterbuck RE, Winslow JW, Cayouette MH, Price DL (1993) Evidence that brain-derived neurotrophic factor is a trophic factor for motor neurons in vivo. Neuron 10:359-367.

Levy D, Tal M, Hoke A, Zochondne DW (2000) Transient action of the endothelial constitutive nitric oxide synthase (ecNOS) mediates the development of thermal hypersensitivity following peripheral nerve injury. Eur J Neurosci 12:2323-2332.

Lindholm D. Heumann R, Meyer M, Thoenen H (1987) Interleukin-1 regulates synthesis of nerve growth factor in non-neuronal cells of rat sciatic nerve. Nature 330:658-659.

Lutomski D, Joubert-Caron R, Lefebure C, Salama J, Belin C, Bladier D,
Caron M (1997) Anti-galectin-1 autoantibodies in serum of patients with neurological diseases. Clinica Chimica Acta 262:131-138.

Peiser L, Gough PJ, Darley E, Gordon S, (2000) Characterization of macrophage antigens and receptors by immunochemistry and fluorescent analysis: expression, endocytosis, and phagocytosis. In: Macrophage (Paulnock DM, ed). New York: Oxford UP.

Perillo NL, Marcus ME, Baum LG (1998) Galectins: versatile modulators of cell adhesion, cell proliferation, and cell death. J Mol Med 76:402-412.

Perry VH (1994) Macrophages in peripheral nerve repair. In: Macrophages and the nervous system. Austin, Texas: RG Landes.

Pu S-F, Zhuang H-X, Ishii DN (1995) Differential spatio-temporal expression of the insulin-like growth factor genes in regenerating sciatic nerve. Mol Brain Res 34:18-28.

Rapalino O, Lazarov-Spiegler O, Agranov E, Velan GJ, Yoles E, Fraidakis M, Solomon A, Gepstein R, Katz A, Belkin M, Hadani M, Schwartz M (1999) Implantation of stimulated homologous macrophages results in partial recovery of paraplegic rats. Nat Med 4:814-821.

Regan LJ, Dodd J, Barondes SH, Jessell TM (1986) Selective expression of endogenous lactose-binding lectins and lactoseries glycoconjugates in subsets of rat sensory neurons. Proc Natl Acad Sci USA 83:2248-2252.

Ricci A, Greco S, Mariotta S, Felici L, Amenta F, Bronzette E (2000) Neurotrophin and neurotrophin receptor expression in alveolar macrophages: an immunocytochemical study. Growth Factors 18:193-202.

Schwartz M, Moalem G, Leibowitz-Amit R, Cohen R (1999) Innate and adaptive immune responses can be beneficial for ZCNS repair. Trends Neurosci 22:295-299.

Sendtner M, Schmalbruch H, Stöckli KA, Carroll P, Kreutzberg GW, Thoenen H (1992) Ciliary neurotrophic factor prevents degeneration of motor neurons in mouse mutant progressive motor neuropathy. Nature 358:502-504.

Shuto T, Horie H, Hikawa N, Sango K, Tokashiki A, Murata H, Yamamoto I, Ishikawa Y (2001) IL-6 upregulates CNTF mRNA expression and enhances neurite regeneration. NeuroReport 12:1081-1085.

Tracey BM, Feizi T, Abbott WM, Carruthers RA, Green BN, Lawson AM (1992) Subunit molecular mass assignment of 14.654 Da to the soluble $\beta$-galactoside-binding lectin from bovine heart muscle and demonstration of intramolecular disulfide bonding associated with oxidative inactivation. J Biol Chem 267:10342-10347.

Verge VMK, Riopelle RJ, Richardson PM (1989) Nerve growth factor receptors on normal and injured sensory neurons. J Neurosci 9:914-922.

Yan Q, Elliot J, Snide WD (1992) Brain-derived neurotrophic factor rescues spinal motor neurons from axotomy-induced cell death. Nature 360:753-755.

Yin Y, Cui Q, Li Y, Irwin N, Fischer D, Harvey, Benowitz LI (2003) Macrophage-derived factors stimulate optic nerve regeneration. J Neurosci 23:2284-2293. 